\title{
Spinal Epidural Infection
}

\author{
N. A. RUSSELL, RICHARD VAUGHAN AND T. P. MORLEY
}

SUMMARY: Thirty cases of spinal epidural abscess are reviewed with particular emphasis on mode of presentation and results of treatment. In spite of repeated exhortations in the literature for earlier diagnosis, the results remain unsatisfactory because many patients have progressed to severe or complete paralysis before the correct diagnosis is made and surgical treatment carried out.

RÉSUMÉ: Nous étudions trente cas d'abcès spinaux épiduraux avec emphase particulière sur le mode de présentation et le résultat du traitement. Malgré de nombreuses requêtes dans la littérature en faveur d'un diagnostic précoce, les résultats demeurent insatisfaisants parce que plusieurs patients ont déjà progressé à une paralysie sévère ou complète avant que le diagnostic ne soit fait et que le traitement chirurgical ne soit entrepris.

From the Division of Neurosurgery, Toronto General Hospital.

Reprint requests to: Dr. T. P. Morley, Division of Neurosurgery, Toronto General Hospital, Toronto, Ontario MSG $1 \mathrm{~L} 7$.

\section{INTRODUCTION}

Pyogenic infection of the epidural space of the spinal canal is uncommon. In a recent series of central nervous system abscesses reported by de Louvois et al. (1977), there were 3 spinal epidural abscesses compared to 43 intracranial. Dandy (1926) reported 3 cases successfully treated by operation, and reviewed from the literature a further 28 cases of nontuberculous infection. Of these, only 4 patients survived for longer than one year, but the majority did not receive operative treatment. Mixter and Smithwick (1932) reviewed their experience with 10 cases and reported a mortality rate of $70 \%$. Browder and Myers (1937) reported 7 cases with 5 deaths. Other substantial series have been reported by Heusner (1948), Hulme and Dott (1954), Hancock (1973), and by Baker et al. (1975).

The clinical features associated with spinal epidural abscess should by now be well recognized, but the diagnosis is still often not made before severe neurological deterioration has set in. The purpose of this article is to review the clinical features and management of a group of spinal epidural infections to discover if the clinical presentation has changed or treatment improved since the earlier reports appeared.

\section{MATERIAL}

Thirty patients with spinal epidural abscess have been treated since 1946 in the division of neurosurgery. This is slightly less than one case a year, or about one for every 1,000 patients admitted to the division. There were 15 males and 15 females who ranged in age from 19 to 75 years.

\section{SIGNS AND SYMPTOMS}

Intractable, severe spinal pain was the first symptom in 23 patients and a major symptom in all. Pain around the trunk or down the legs was the second commonest symptom. Sensorimotor impairment was next in frequency and ranged from total paraplegia with sphincter involvement, through severe weakness with spinothalamic loss but relative preservation of posterior column sensation (major paraparesis), to minor weakness with patchy sensory loss (minor paraparesis). Dissociated spinothalamic sensory loss occurred in 6 cases, a finding which may not be so uncommon as Davidson and Zajac (1978) have suggested. Muscle spasms, headache, and neck stiffness occasionally occurred. Twenty-three patients were febrile upon admission.

\section{ASSOCIATED DISEASE}

Ten patients were debilitated by diabetes and/or alcoholic liver disease; one had congestive heart failure, obesity, and hypothyroidism. The source of infection was known in 19 cases. Eight had had non-spinal surgery and 3 "clean" surgery related to the spine (Table I), and 8 had received no previous operation (Table II).

\section{ANATOMIC DISTRIBUTION} (Table III)

The dorsal region of the cord was most frequently involved. There were only 2 cases in which the infection was limited to the cervical spine. Dandy (1926) suggested that the absence of a fat-containing epidural space in the cervical region protects it from infection, an opinion supported by Durity and Thompson (1968).

\section{DIAGNOSIS}

Plain radiographs showed evidence of inflammatory disease of bone in 11 patients and extradural obstruction was found in all 25 patients in whom 
TABLE I

Spinal Epidural Infection

Previous surgery related to source of infection.

Elective spinal operations

for non-inflammatory disease

Insertion knee prosthesis

Appendix abscess

Hemorrhoidectomy

Endoscopic prostatic resection

Cystoscopy

Varicose ulcer

Toe gangrene

Occipital epidermoid

TABLE II

Spinal Epidural Infection

Source of Infection

No previous surgery

Pneumonia

Furunculosis

Toe paronychia

TABLE III

Spinal Epidural Infection

Distribution

Cervical

Cervico-dorsal

Dorsal

Dorso-lumbar

Lumbo-sacral

TABLE IV

Spinal Epidural Infection

\section{Classification and case distribution}

Acute - hematogen ous

- osteomyelitic

Subacute

Chronic

Following spinal surgery

myelography was performed. CSF analysis was recorded in 19 patients. Protein was raised above $100 \mathrm{mg} \%$ in 14 (up to $1,900 \mathrm{mg}$. per $100 \mathrm{ml}$.). The cell count, predominantly lymphocytes, was raised up to 150 wbc per cu. $\mathrm{mm}$. in 17 , and $933 \mathrm{wbc}$ per cu. mm. in one. Pus was obtained from the spinal puncture on 2 occasions. The white blood cell count was recorded for 22 patients and was higher than 10,000 in 17. The ESR was elevated in the 23 patients in whom it was carried out (range 40-119 $\mathrm{mm} / \mathrm{hr}$.).

Blood cultures were taken in 23 patients but only after antibiotics had been given; 6 were positive for staphylococcus aureus.

Culture of material taken at operation, whether of pus or granulation tissue, was positive in all cases. Staphylococcus aureus was grown from 28 and actinomyces bovis from 1 case.

\section{CLASSIFICATION}

Our classification (Table IV) conforms to some of the earlier reports except that we have placed those cases that followed clean spinal surgery in a separate category. The osteomyelitic subgroup merits separate classification only on the grounds of bone involvement. We do not know if the osteomyelitis was primary or secondary to the epidural infection.

A breakdown of the presenting symptoms and signs is shown in Table $\mathrm{V}$.

\section{ACUTE}

Hematogenous (10). In this group there was no radiographic evidence of osteomyelitis and none was found at operation. All patients had severe spinal pain, a fulminating illness, and rapidly worsening neurological deficit. The duration of symptoms before treatment averaged 12 days. Three patients were paraplegic, 4 had severe sensorimotor weakness almost to the point of paraplegia by the time of operation, and the other 3 had minor leg weakness.

Osteomyelitic (4). All had severe spinal pain with prominent signs of meningeal irritation. The duration of symptoms averaged 13 days. There were 2 patients in each of the major and minor paraparesis categories.

\section{SUBACUTE: (8)}

The common complaint was nagging, persistent spinal ache for up to 90 days before diagnosis. Gradual impairment of sensation and leg strength developed, with headache and neck stiffness. One patient had major and 7 had minor weakness.

CHRONIC: (5)

Three out of 5 patients had vertebral osteomyelitis with kyphotic deformity. Chronic spinal pain and slow development of weakness and sensory change extended over an average period of 150 days. One patient was paraplegic when first seen, one severely quadriparetic, another severely paraparetic, and 2 had minor weakness.

\section{COMPLICATION OF CLEAN} SPINAL SURGERY: (3)

One patient had undergone a Hibb's type of spinal fusion for correction of gross kyphoscoliosis. Fever persisted from the evening of operation. Paraesthesiae in the legs developed 4 days later, followed by the onset of weakness which by the twelfth day had progressed to paraplegia.

In 2 patients purulent discharge from the wound was followed by spinal pain and the gradual onset of leg weakness; the symptoms extended over a period of 4 months.

\section{TREATMENT}

Twenty-nine of the 30 cases were treated by wide decompressive laminectomy with evacuation of the purulent material and granulations. Bacitracin solution was used to irrigate the wounds. In one case a tube was left in the epidural space and continuous irrigation with methicillin was carried out for 48 hours. The other cases were closed without drainage. All cases received postoperative antibiotics and 24 received antibiotics preoperatively. One patient who declined operation was treated with antibiotics and immobilization on a Stryker frame and became paraplegic.

The findings at operation matched the clinical classification in each main grouping with one exception in the acute group. This patient presented with a history of neck pain for 3 days followed rapidly by quadriplegia. At operation a firm cervical extradural granuloma was excised. No visible pus was seen though the culture was 
positive for staphylococcus aureus. From the pathological standpoint, then, this patient was in the chronic group and was the only case in which the duration of symptoms did not correlate with the pathological finding. There was no indication from the history, even in retrospect, how long the epidural space had been infected.

In the acute group, pus was always present with varying amounts of red granulation tissue, but when only a little granulation tissue was found posteriorly, pus could eventually be found anteriorly by opening the dura longitudinally and then incising it laterally. This was accomplished in 4 patients without precipitating meningitis. The dura was opened on another occasion for decompression at a second operation in a patient who had deteriorated following the original procedure. Pus had tracked into the paraspinal muscles in 3 of the hematogenous group.

In the subacute group beads of pus were found embedded in relatively friable, white granulation tissue. Pus was not found in the chronic group where the epidural space was occupied by adherent, greyish-white granulation tissue or maturing fibrous tissue.

\section{EVALUATION OF TREATMENT}

The results of treatment are shown in Table VI. There was no improvement in the 5 cases who were paraplegic before operation. Eleven made complete recovery. Eight were able to walk independently and had normal sphincter function, but were left with varying degrees of minor spasticity and with spinothalamic sensory loss. One patient was left with severe paraparesis. The patient who declined operation became paraplegic.

The extent of neurological recovery correlated with the degree of preoperative preservation of cord function.

\section{MORTALITY}

One patient died from septicemia. The other 3 deaths were due, respectively, to aplastic anemia secondary to antibiotic therapy in a patient with metastatic abscesses,

TABLE V

Spinal Epidural Infection

\begin{tabular}{|c|c|c|c|c|}
\hline \multicolumn{5}{|c|}{ Clinical Presentation } \\
\hline & $\begin{array}{l}\text { DURATION OF SYMPTOMS } \\
\text { (average days) }\end{array}$ & PARAPLEGIC & $\begin{array}{c}\text { MAJOR } \\
\text { PARAPARESIS }\end{array}$ & $\begin{array}{c}\text { MINOR } \\
\text { PARAPARESIS }\end{array}$ \\
\hline Acute - hematogenous $(10)^{*}$ & 12 & 3 & 4 & 3 \\
\hline —osteomyelitic (4) & 13 & 0 & 2 & 2 \\
\hline Subacute $(8)$ & 90 & 0 & 1 & 7 \\
\hline Chronic (5) & 150 & 1 & 2 & 2 \\
\hline \multicolumn{5}{|l|}{ Following spinal surgery (3) } \\
\hline - acute & $12(1)$ & 1 & 0 & 0 \\
\hline \multirow[t]{2}{*}{ - chronic } & $120(2)$ & 0 & 0 & 0 \\
\hline & & 5 & 9 & 14 \\
\hline
\end{tabular}

*numbers in parentheses are the number of patients.

TABLE VI

Spinal Epidural Infection

\begin{tabular}{|c|c|c|c|c|c|}
\hline \multicolumn{6}{|c|}{ Results of Treatment } \\
\hline & PARAPLEGIC & $\begin{array}{c}\text { MAJOR } \\
\text { PARAPARESIS }\end{array}$ & $\begin{array}{c}\text { MINOR } \\
\text { DEFECTS }\end{array}$ & NORMAL & DEAD \\
\hline Acute - hematogenous (10) & 3 & 0 & 3 & 3 & 1 \\
\hline - osteomyelitic (4) & 0 & 0 & 1 & 2 & 1 \\
\hline \multirow[t]{2}{*}{ Subacute (8) } & 1 & 0 & 3 & 3 & 1 \\
\hline & (no opn.) & & & & (no opn.) \\
\hline Chronic (5) & 1 & 1 & 1 & 1 & 1 \\
\hline \multicolumn{6}{|l|}{ Following spinal surgery } \\
\hline - acute (1) & 1 & 0 & 0 & 0 & 0 \\
\hline \multirow[t]{2}{*}{ - subacute (2) } & 0 & 0 & 0 & 2 & 0 \\
\hline & 6 & 1 & 8 & 11 & 4 \\
\hline
\end{tabular}


pulmonary embolism, and congestive heart failure.

Post mortem examination was performed in the 4 fatal cases. It showed (i) preservation, without thrombosis, of the arterial supply of the cord, (ii) compression, thrombosis, and thrombophlebitis of the veins of the cord and epidural space and (iii) venous infarction and edema of the cord.

\section{DISCUSSION}

It has been the convention in most previous reports to recognize only the acute and chronic (granuloma) subdivisions of spinal epidural abscess. We have classified our cases as acute, subacute, and chronic according to duration of symptoms. This correlated with the pathological findings at operation in all but one case (see above).

The source of infection, when it could be traced, preceded the first spinal symptoms by several days or weeks. Midline back pain or spinal ache progressed to severe pain, frequently with local tenderness; radiating pain may then develop as the roots become involved. Finally, neurologic deficit advanced to paraplegia. Spinal pain was most severe in the acute group and was often confused with disc herniation or inflammatory joint disease, a diagnostic error which was even more common when root pain and sensory loss were added to the symptom complex. In other cases, root pain and sensory loss were mistaken for part of a polyneuropathy associated with an infectious disease. Fever and other systemic signs of infection were sometimes so prominent in the acute group that spinal pain and tenderness were ignored. There was little symptomatic difference between the osteomyelitic and hematogenous groups except that in the latter weakness was usually more severe. Chronic cases tended to be mistaken for benign tumors since local and systemic evidence of inflammation was lacking. The clinical presentation over the whole series has not changed in any important respect from earlier reports.
Early postoperative wound infection without neurological deterioration occurred in 5 patients. All healed by secondary intention after the original wound had been opened and packed. Wound infection was most frequent in the subacute group.

In our cases of elective disc surgery, postoperative wound infection, apparently superficial, was the first sign of infection in the disc space itself. On the other hand, Thibodeau (1967), reporting 50 such cases collected over 18 years, found that disc space infection occurred more frequently (41 cases) without external discharge of pus or other visible sign of infection than when these signs were present $(9$ cases).

Staphylococcus aureus was recovered from 27 of the 28 patients who were treated by operation. This is similar to the high incidence of staphylococcus in the early reports, but differs from the experience of Baker et al. (1975) who found staphylococcus in only $54 \%$ of their cases.

Dandy's prediction that early operation would improve the high mortality rate prevailing at the time was correct, but for a reason he could not then clearly see. Before World War II, paraplegia carried a prognosis for survival which was counted in months because the complications of paraplegia were neither prevented nor cured. Although he did not explicitly say so, Dandy would have acknowledged that benefit from early operation was due to the prevention of paraplegia and hence death from its complications. The other main cause of death before the War was septicemia which could be prevented by timely surgical drainage. Today's improved survival figures are mainly due to incomparably superior management of paraplegia, and in part due to the treatment and prevention of septicemia by antibiotics. The fundamental importance of surgical drainage of pus, in the spinal canal as elsewhere, has not been diminished by the use of antibiotics.

With the mortality rate reduced to more acceptable levels, we now strive for improvement in the final functional result. This can only be achieved by still earlier diagnosis, for preservation of cord function depends directly on preoperative neurological integrity. Unfortunately, there is little evidence from our experience that diagnosis is arrived at any earlier today than in earlier reports. Of our 30 cases 5 were paraplegic and 10 were severely paraparetic before they were presented for surgical treatment.

\section{ACKNOWLEDGEMENTS}

The authors thank their neurosurgical colleagues Drs. W. M. Lougheed, R. R. Tasker, and I. B. Schacter for permission to include their cases in this report

\section{REFERENCES}

BAKER, A. S., OJEMANN, R. G., SWARTZ, M. N. and RICHARDSON, E. P. (1975) Spinal epidural abscess. New Eng. J. Med. 293:463-468.

BROWDER, J. and MEYERS, R. (1937). Infections of the spinal epidural space: an aspect of vertebral osteomyelitis. Amer. J. Surg. 37 (new series): 4-26.

DANDY, W. E. (1926). Abscesses and inflammatory tumors in the spinal epidural space (so-called pachymeningitis externa). Arch. Surg. 13:477-494.

DAVIDSON, R. I. and ZAJAC, J. J. (1978) Spinal epidural empyema with the BrownSéquard syndrome. Surg. Neurol. 9:195-197.

DURITY, F., and THOMPSON, G. B. (1968). Localized cervical extradural abscess. J. Neurosurg. 28:387-390.

HANCOCK, D. O. (1973). A study of 49 patients with acute spinal extradural abscess. Paraplegia 10:285-288.

HEUSNER, A. P. (1948). Non-tuberculous spinal epidural infections. New Eng. J. Med. 239:845-854

HULME. A. and DOTT, N. M. (1954). Spinal epidural abscess. Brit. Med. J. 1:64-69.

de LOUVOIS, J., GORTVAI, P. and HURLEY, R. (1977). Bacteriology of abscesses of the central nervous system: a multicentre prospective study. Brit. Med. J. 2:981-984.

MIXTER, W. J, and SMITHWICK, R. H (1932). Acute intraspinal epidural abscess New Eng. J. Med. 207:126-131.

THIBODEAU, A. A. (1967). Closed space infection following removal of lumbar intervertebral disc. Clinical Neurosurgery 14:337-360. 